\title{
Genetic diversity and differentiation of the endangered and endemic species Sauvagesia rhodoleuca in China as detected by ISSR analysis
}

\author{
S.F. Chai ${ }^{1,2}$, Y.S. Jiang ${ }^{2}$, X.Y. Zhuang ${ }^{1}$, Y.C. Shi ${ }^{2}$, X. Wei ${ }^{2}$, W.H. Luo ${ }^{2}$ and \\ Z.Y. Chen ${ }^{2}$ \\ ${ }^{1}$ College of Forestry, South China Agricultural University, Guangzhou, China \\ ${ }^{2}$ Guangxi Institute of Botany, \\ Guangxi Zhuangzu Autonomous Region and the Chinese Academy of Sciences, \\ Guilin, China \\ Corresponding author: X. Wei \\ E-mail: weixiao@gxib.cn
}

Genet. Mol. Res. 13 (4): 8258-8267 (2014)

Received January 3, 2013

Accepted May 23, 2013

Published October 20, 2014

DOI http://dx.doi.org/10.4238/2014.October.20.2

\begin{abstract}
Sauvagesia rhodoleuca (Ochnaceae) is an endangered plant that is endemic to southern China. The levels of genetic variation and patterns of population structure in $S$. rhodoleuca were investigated using inter-simple sequence repeat markers. Eleven primers were used to amplify DNA samples from 117 individuals, and a total of 92 loci were detected. Our results indicated that genetic diversity was quite low both at the species level (percentage of polymorphic bands (PPB) $=41.30 \%$, Nei's gene diversity $(h)=0.1331$, and Shannon information index $(I)=0.2028)$ and the population level $(\mathrm{PPB}=16.30-28.26 \%$, $h=0.0496-0.1012$, and $I=0.0756-0.1508)$. A high level of genetic differentiation among populations was detected based on Nei's genetic diversity analysis (0.4344) and analysis of molecular variance $(47.03 \%)$. The low genetic diversity within population and high population
\end{abstract}


differentiation of $S$. rhodoleuca were assumed to result largely from limited gene flow, genetic drift, inbreeding, and clonal growth. Conservation strategies for this endangered species are proposed based on the genetic data.

Key words: Endangered plant; Inter-simple sequence repeat; Sauvagesia rhodoleuca; Genetic diversity; Genetic differentiation

\section{INTRODUCTION}

The World Conservation Union has recommended the conservation of intraspecific genetic variation as 1 of the 3 focal levels of biodiversity conservation (McNeely et al., 1990). Genetic diversity is necessary for populations to evolve in response to future environmental change (Frankham et al., 2002). The loss of genetic variation is usually accompanied by a reduction of the species' ability to cope with changes in the environment, which causes the species to become rare (Maki and Horie, 1999; Frankham et al., 2002).

Endemic species with restricted geographic distributions have become a central concern of biologists that are faced with the problem of preserving rare species that are endangered by habitat destruction and fragmentation. Endemic species often exist in small and isolated populations. These populations are susceptible to losing their genetic diversity because of accelerated inbreeding and genetic drift, the reproductive ability and viability of the individuals within them can be reduced; additionally, their ability to adapt to environmental changes can be compromised, consequently leading to the extinction of these populations (Jeong et al., 2010).

In principle, the genetic diversity and structure of plant populations are highly dependent on the population size, gene flow, and life cycle of a species (Nybom and Bartish, 2000). Endangered plant species often exhibit low levels of genetic diversity because of genetic drift or bottleneck effects (Wei et al., 2005; Haque et al., 2010), but they can also exhibit diverse levels of genetic variation because of different life history characteristics, distributions, and habitats (Feyissa et al., 2007; Verma and Rana, 2011). The knowledge of population genetic diversity and structure can provide important information to understand the evolution of rare and endangered species and to plan for their conservation, for example, by identifying populations with the greatest evolutionary potential and best suited as a source material for ex situ preservation or reintroduction (Furches et al., 2009). Therefore, to establish strategies to preserve an endangered species, the level of genetic diversity within and among populations should be studied in its distribution areas.

Sauvagesia rhodoleuca, a perennial dwarf shrub, is endemic to southern China. It only occurs in the Guangxi Zhuangzu Autonomous Region and Guangdong Province, occurring primarily in shady and moist habitats near streams and at an altitude of 200-800 m (Fen and Amaral, 1984). Because of its high phylogenetic, ecological, and medicinal significance, it has attracted considerable attention. However, $S$. rhodoleuca is highly vulnerable to environmental changes (Liang, 2006). According to a previous report (He and Li, 2005) and our field survey, the habitats of this species have been severely deteriorated and fragmented largely due to anthropogenic activities (e.g., deforestation, over-exploitation), and its natural populations have shrunk to small sizes. For example, most populations in this study were observed to have only 100-200 individuals (Table 1). Thus, S. rhodoleuca has been listed in Category I of state protected key wildlife in China (The State Forestry Administration and Ministry of 
Agriculture, 1999). Previous studies on S. rhodoleuca have mainly focused on its biological characteristics (Liang, 2006), seed germination (Chai et al., 2010) and vegetative propagation using cuttings (Zeng et al., 2010). However, the genetic diversity within and among $S$. rhodoleuca populations has not been investigated.

Inter-simple sequence repeats (ISSRs) are highly variable, exhibit Mendelian inheritance, and have been used widely in population genetic studies because they require less time, money, and labor than other markers to analyze (Gupta et al., 1994; Wolfe and Liston, 1998; Harris, 1999). In our study, ISSR markers were applied to detect the genetic diversity of $S$. rhodoleuca across its main current geographic range. Our principle objectives were 1) to assess levels of genetic diversity of natural populations, 2) to examine the degree of differentiation among populations, and 3 ) to provide basic information for establishing management practices to preserve this endangered species.

\section{MATERIAL AND METHODS}

\section{Plant materials}

According to previous records, S. rhodoleuca was discovered in Rongshui, Luocheng, Huanjiang, Jinxiu, and Debao County, Guangxi Zhuangzu Autonomous Region, and Huaiji, Fengkai, and Lianshan County, Guangdong Province (Fen and Amaral, 1984; Wang et al., 1994). However, only 5 populations (Figure 1 and Table 1) can be found at present, and the other 3 populations ultimately became extinct between the last records and when we sampled the regions in 2008. Young leaves were collected from 21 to 24 individuals in each population, and the distances between neighboring plants were at least 3-5 m apart to avoid sampling from the same rhizomes. The leaf tissues were stored in ziplock bags with silica gel and transported back to the laboratory for DNA extraction.

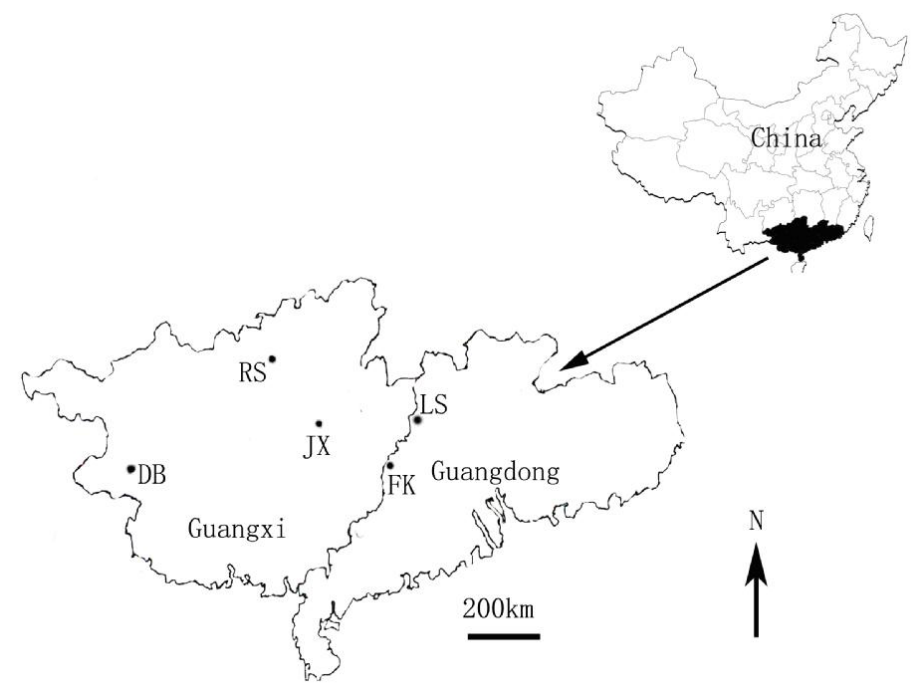

Figure 1. Geographic distribution of the 5 Sauvagesia rhodoleuca populations sampled in China. For population abbreviations, see Table 1. 


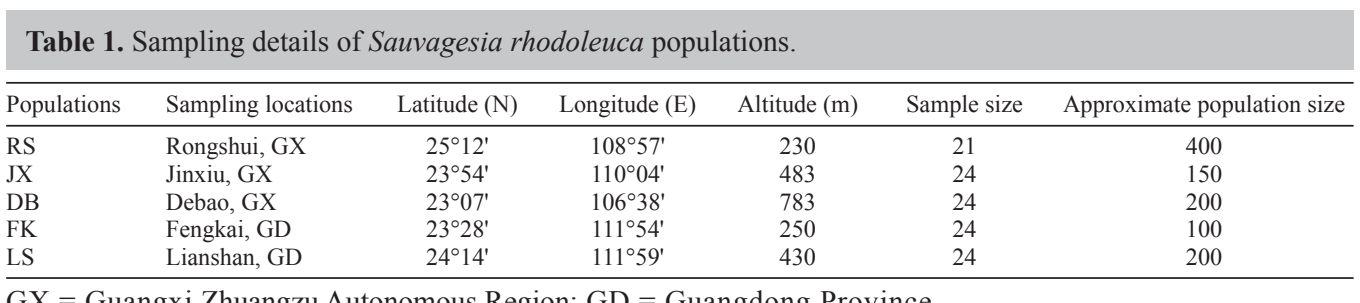

\section{DNA extraction}

Genomic DNA was extracted using the cetyltrimethylammonium bromide (CTAB) method (Doyle and Doyle, 1988). DNA quality and quantity were determined on $1.0 \%$ agarose gels. The DNA samples were diluted to $20 \mathrm{ng} / \mu \mathrm{L}$ and stored at $-20^{\circ} \mathrm{C}$ until further analysis.

\section{ISSR-polymerase chain reaction (PCR) amplification}

The ISSR primers that were used in this study were synthesized by Shanghai Sangon Biological Engineering Technology and Service Co., Ltd. according to the primer set of University of British Columbia (http://www.michaelsmith.ubc.ca/services/NAPS/Primer_Sets/Primers Oct2006.pdf). One hundred primers were initially screened for PCR amplification, and 11 of them that yielded clear and reproducible banding patterns were selected for final analyses (Table 2). PCR amplification was repeated for the 11 primers to check the stability and reproducibility of ISSR fragments. PCR amplification was carried out in a total volume of $20 \mu \mathrm{L}$, containing $20 \mathrm{ng}$ genomic DNA, $0.4 \mu \mathrm{M}$ primer and $10 \mu \mathrm{L} 2 \mathrm{X}$ Taq PCR MasterMix ( $0.1 \mathrm{U}$ Taq Polymerase/ $\mu \mathrm{L}, 0.5$ $\mathrm{mM}$ of each dNTP, $3.0 \mathrm{mM} \mathrm{MgCl}, 20 \mathrm{mM}$ Tris-HCl, $\mathrm{pH} 8.3,100 \mathrm{mM} \mathrm{KCl}$ ) (Tiangen Biotech, China). PCR amplification was performed in a Biometra TProfessional Thermocycler with the following protocol: $5 \mathrm{~min}$ at $94^{\circ} \mathrm{C} ; 35$ cycles of $30 \mathrm{~s}$ at $94^{\circ} \mathrm{C}, 45 \mathrm{~s}$ at $52^{\circ} \mathrm{C}$, and $90 \mathrm{~s}$ at $72^{\circ} \mathrm{C}$; and a final 7 -min extension step at $72^{\circ} \mathrm{C}$. The negative control was run by replacing template DNA with $\mathrm{ddH}_{2} \mathrm{O}$ to test for the possibility of contamination. Amplification products were electrophoresed on $1.8 \%$ agarose gels, stained with ethidium bromide, visualized under ultraviolet light, and photographed. Molecular weights were estimated using a 100-bp DNA ladder (Takara Biotech).

\section{Data analysis}

ISSR-amplified bands were scored as 1 (present) or 0 (absent). Only those amplified fragments that were clear and reproducible were included in the analysis. The resulting binary data matrix was analyzed using POGENE Version 1.32 (Yeh et al., 1997). The genetic diversity within and among populations was measured by the percentage of polymorphic bands (PPB), observed number of alleles $\left(N_{\mathrm{A}}\right)$, effective number of alleles $\left(N_{\mathrm{E}}\right)$, Nei's gene diversity $(h)$, and Shannon's information index $(I)$. The genetic differentiation among populations was estimated by the gene differentiation coefficient $\left(G_{\mathrm{ST}}\right)$ (Nei, 1973). The gene flow $\left(N_{\mathrm{m}}\right)$, the average number of migrants that were exchanged among populations per generation, was estimated as $N_{\mathrm{m}}=\left(1 / G_{\mathrm{ST}}-1\right) / 4$ (McDermott and McDonald, 1993). All of these calculations assumed that populations are in Hardy-Weinberg equilibrium. The genetic divergence between populations was estimated by unbiased genetic distances and genetic identities (Nei, 1972). 
These distances were used to construct an unweighted pair group method with arithmetic mean (UPGMA) dendrogram using NTSYSpc 2.02 (Rohlf, 1998).

Analysis of molecular variance (AMOVA) was performed using squared Euclidean distances to partition genetic diversity within and between populations. All analyses were carried out using WINAMOVA 1.55 (Excoffier and Hamrick, 1993). Input files for this program were generated using AMOVA-PREP. The significance was tested using 1000 permutations. To test the correlation between genetic and geographic distances $(\mathrm{km})$ among populations, a Mantel test was performed using tools for population genetic analyses (Miller, 1997) with 999 permutations.

\section{RESULTS}

\section{Genetic diversity}

From the 117 individuals of $S$. rhodoleuca from 5 populations, the 11 selected primers generated 92 unambiguous and reproducible bands. Of these, 38 bands were polymorphic (PPB $=41.30 \%$ ). Each primer yielded between 6 and 12 bands (Table 2), ranging in size from 200 to $2200 \mathrm{bp}$. At the species level, the genetic diversities that were measured by $N_{\mathrm{A}}, N_{\mathrm{E}}$, $h$, and $I$ were $1.4130,1.2220,0.1331$, and 0.2028 , respectively (Table 3 ). At the population level, the PPB ranged from 16.30 to $28.26 \%$ with a mean of $21.96 \%, h$ ranged from 0.0496 to 0.1012 with a mean of 0.0758 , and $I$ ranged from 0.0756 to 0.1508 with a mean of 0.1135 . Among the 5 populations, the highest level of genetic diversity occurred in population RS $\left(N_{\mathrm{A}}=1.2826, N_{\mathrm{E}}=\right.$ $1.1735, h=0.1012, I=0.1508$, and PPB $=28.26 \%)$, while the lowest was in FK $\left(N_{\mathrm{A}}=1.1630\right.$, $N_{\mathrm{E}}=1.0849, h=0.0496, I=0.0756$, and PPB $\left.=16.30 \%\right)($ Table 3$)$.

\begin{tabular}{|c|c|c|c|}
\hline Primer & Sequence $\left(5^{\prime}-3^{\prime}\right)$ & B & $\mathrm{P}$ \\
\hline 812 & $(\mathrm{GA})_{8} \mathrm{~A}$ & 8 & 1 \\
\hline 823 & (TC) ${ }_{8} \mathrm{C}$ & 6 & 2 \\
\hline 840 & $(\mathrm{GA})_{8} \mathrm{YT}$ & 11 & 6 \\
\hline 842 & $(\mathrm{GA}) \mathrm{YG}$ & 7 & 1 \\
\hline 855 & $(\mathrm{AC})_{8} \mathrm{YT}^{\mathrm{T}}$ & 10 & 2 \\
\hline 857 & $(\mathrm{AC})_{8}^{8} \mathrm{YG}$ & 9 & 3 \\
\hline 868 & $(\mathrm{GAA})_{5}$ & 6 & 3 \\
\hline 895 & AGA GTT GGT AGC TCT TGA TC & 12 & 8 \\
\hline 896 & AGG TCG CGG CCG CNN NNN NAT G & 9 & 5 \\
\hline 899 & CAT GGT GTT GGT CAT TGT TCC A & 8 & 5 \\
\hline 900 & ACT TCC CCA CAG GTT AAC ACA & 6 & 2 \\
\hline Total & & 92 & 38 \\
\hline
\end{tabular}

$\mathrm{N}=(\mathrm{A}, \mathrm{G}, \mathrm{C}, \mathrm{T}) ; \mathrm{Y}=(\mathrm{C}, \mathrm{T})$.

Table 3. Genetic diversity within populations of Sauvagesia rhodoleuca.
\begin{tabular}{lccccc}
\hline Populations & $N_{\mathrm{A}}$ & $N_{\mathrm{E}}$ & $h$ & $I$ & PPB (\%) \\
\hline RS & 1.2826 & 1.1735 & 0.1012 & 0.1508 & 28.26 \\
JX & 1.1848 & 1.1071 & 0.0636 & 0.0957 & 18.48 \\
DB & 1.2609 & 1.1576 & 0.0912 & 0.1360 & 26.09 \\
FK & 1.1630 & 1.0849 & 0.0496 & 0.0756 & 16.30 \\
LS & 1.2065 & 1.1280 & 0.0735 & 0.1095 & 20.65 \\
Mean population level & 1.2196 & 1.1302 & 0.0758 & 0.1135 & 21.96 \\
Species level & 1.4130 & 1.2220 & 0.1331 & 0.2028 & 41.30 \\
\hline
\end{tabular}

$N_{\mathrm{A}}=$ observed number of alleles per locus; $N_{\mathrm{E}}=$ effective number of alleles per locus; $h=$ expected heterozygosity; $I=$ Shannon's information index; $\mathrm{PPB}=$ percentage of polymorphic bands. 


\section{Genetic differentiation}

The genetic differentiation $\left(G_{\mathrm{ST}}\right)$ among populations was 0.4344 , which indicates that $43.44 \%$ of the genetic variability is among populations, and $56.56 \%$ is within populations. These are comparable with the variance partitions among and within populations from AMOVA (Table 4). The gene flow was estimated to be low $\left(N_{\mathrm{m}}=0.6511\right)$.

Table 4. Analysis of molecular variance for populations of Sauvagesia rhodoleuca.
\begin{tabular}{lrcccccc}
\hline Source of variation & d.f. & Sum of squares & Mean squares & Variance components & Percentage of variance & P value \\
\hline Among populations & 4 & 284.78 & 71.19 & 2.90 & $47.03 \%$ & $<0.001$ \\
Within populations & 112 & 366.35 & 3.27 & 3.27 & $52.97 \%$ & $<0.001$ \\
\hline
\end{tabular}

d.f. $=$ degrees of freedom.

\section{Genetic relationship among populations}

Table 5 presents Nei's genetic identities and genetic distance for all population pairs. The highest genetic distance was 0.1301 between populations RS and JX, while the lowest was 0.0508 between JX and FK. The UPGMA dendrogram shows that the 5 populations form 2 major clusters, with JX and FK in one cluster and RS, DB, and LS in another (Figure 2). Among the population pairs, the geographic distance between FK and LS was the shortest $(86.8 \mathrm{~km})$, but they are not grouped into a cluster; while the distance is the longest between DB and LS (560.3 km), yet they are grouped into one cluster. Thus, the UPGMA tree does not show a correlation between geographic and genetic distances, which is comparable with the result from the Mantel test that did not detect a significant correlation between geographic and genetic distances $(r=-0.3743, \mathrm{P}=0.2120)$.

\begin{tabular}{|c|c|c|c|c|c|}
\hline & RS & $\mathrm{JX}$ & DB & FK & LS \\
\hline RS & - & 0.8780 & 0.9355 & 0.9212 & 0.9237 \\
\hline JX & 0.1301 & - & 0.9144 & 0.9504 & 0.8928 \\
\hline DB & 0.0667 & 0.0895 & - & 0.9356 & 0.9359 \\
\hline FK & 0.0821 & 0.0508 & 0.0666 & - & 0.9259 \\
\hline LS & 0.0794 & 0.1134 & 0.0663 & 0.0770 & - \\
\hline
\end{tabular}

For population abbreviations, see Table 1.

\section{DISCUSSION}

\section{Genetic diversity and differentiation}

Many studies have demonstrated that endangered and endemic species tend to possess low levels of genetic diversity, whereas some others have shown the opposite findings. In this study, our results show that genetic diversities at the species level in S. rhodoleuca are relatively low ( $\mathrm{PPB}=41.30 \%, h=0.1331$, and $I=0.2028)$. These are similar to those that 


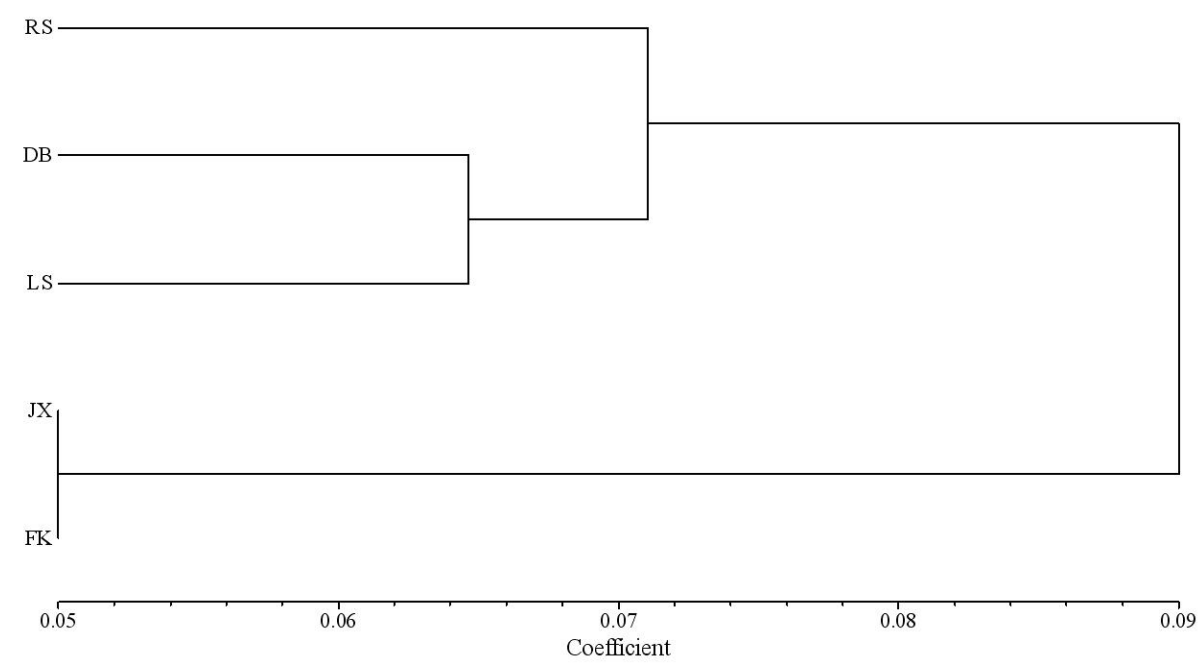

Figure 2. Dendrogram of UPGMA cluster analysis based on Nei's (1972) genetic distances between populations of Sauvagesia rhodoleuca. For population abbreviations, see Table 1.

were reported for some endangered and endemic species in China that were revealed by ISSR, such as Ceratopteris pteridoides ( $\mathrm{PPB}=44.8 \%, h=0.14$, and $I=0.21$ ) (Dong et al., 2007), Omphalogramma souliei (PPB $=42.53 \%, h=0.1135$, and $I=0.1762$ ) (Huang et al., 2009), and Sinopodophyllum hexandrum (PPB $=38.85 \%, h=0.092$, and $I=0.142$ ) (Xiao et al., 2006). However, they are lower than the findings for some other endangered plants, such as Cupressus chengiana (PPB $=99 \%, h=0.3120$, and $I=0.4740$ ) (Hao et al., 2006), Magnolia officinalis (PPB $=83.2 \%, h=0.342$, and $I=0.496$ ) (Yu et al., 2011), and Primula merrilliana $(\mathrm{PPB}=79.56 \%, h=0.25$, and $I=0.38$ ) (Shao et al., 2009). S. rhodoleuca is an endemic species that is found only in a few special locations of Guangxi and Guangdong Province in China. Our results reinforce the hypothesis that endangered species with a narrow distribution are genetically depauperate.

In this study, our data show that the genetic diversities measured by PPB, $h$, and $I$ at the population level are $21.96 \%, 0.0758$, and 0.1135 , respectively, and the genetic differentiation or variability that is attributable to the populations is $43.44 \%$ based on $G_{\mathrm{ST}}$ and $47.03 \%$ based on AMOVA. The genetic structure of plant populations depends on the interactions of various factors, including the long-term evolution history of the species (shifts in distribution, habitat fragmentation, and population isolation), genetic drift, mating system, gene flow, and natural selection (Schaal et al., 1998). The low within-population genetic diversity and high among-population genetic differentiation of $S$. rhodoleuca were assumed to result largely from limited gene flow, genetic drift, inbreeding, and clonal growth, which are discussed in the following paragraphs.

Gene flow is considered the main factor that could homogenize the population genetic structure (Slatkin, 1987). Generally speaking, species with low gene flow have a higher genetic differentiation than those with high gene flow. Differentiation among populations with $N_{\mathrm{m}}<1.0$ would mainly result from the limited gene flow in a condition of high selective pressure or discontinuous distributions (Slatkin, 1987). In our study, $N_{\mathrm{m}}$ among the S. rhodoleuca 
populations was estimated at 0.6511 , indicating a high degree of genetic differentiation among populations. S. rhodoleuca is a habitat-restricted species; it is exclusively confined to thick forests near valleys and streams, and it cannot tolerate high light and drought $(\mathrm{Fu}, 1992)$. Its fragmented habitat and isolated populations have reduced gene flow among populations. In this study, the smallest inter-population distance was $86.8 \mathrm{~km}$; this largely hindered gene flow via seed and pollen dispersal among populations. Its seeds are oval and relatively small in size (length $=0.152 \mathrm{~mm}$, diameter $=0.068 \mathrm{~mm}$, weight per 1000 seeds $=0.631 \mathrm{~g}$ ) (Chai et al., 2010) and are spread mainly by gravity or attachment to animal coats. Although this mechanism is probably effective for short-range dispersal, it might not be effective for gene exchanges between distant populations. Therefore, populations of $S$. rhodoleuca appear to be acting as independent evolutionary units because of limited gene flow.

Genetic drift and inbreeding may be other factors that lead to low intra-population genetic diversity and high inter-population genetic differentiation. According to our field observations, populations of $S$. rhodoleuca are dramatically shrinking in China because of heavy deforestation and extensive habitat loss in the past decades. It was previously reported that there was a distribution of S. rhodoleuca in Huangiiang and Luocheng County in Guangxi (Wang et al., 1994), but we failed to locate the species in these areas. The size of the natural populations of S. rhodoleuca has also decreased (He and $\mathrm{Li}, 2005)$, with current population sizes in the range of several hundred individuals. The species has been gradually fragmented into small, island-like populations. Two major genetic consequences of small population size for long periods of time are high levels of genetic drift and inbreeding (Ellstrand and Elam, 1993). The Mantel test showed there was no correlation between geographic and genetic distance among $S$. rhodoleuca populations. As discussed in other studies (Fischer et al., 2000), the absence of such a correlation suggests an important role for genetic drift in $S$. rhodoleuca, which agrees with the observed high differentiation among populations. Actually, there was a correlation between population size and genetic diversity in S. rhodoleuca. The population size of FK is the smallest of the 5 populations studied, and we detected the lowest genetic diversity here. Conversely, population RS was the largest population, and it retained the highest genetic diversity. It appeared that some inbreeding had occurred within populations of this species.

Clonal growth may also partly account for the low within-population genetic diversity and high among-population genetic differentiation. Generally, asexually reproducing species exhibit low levels of population genetic diversity, whereas sexually reproducing species show high levels of genetic variation (Loveless and Hamrick, 1984). A consequence of clonal growth is reduced sexual reproduction of outcrossing species and increased inbreeding rates in self-compatible plants (Frankham et al., 2002). In our field survey, we observed that S. rhodoleuca produced buds from rhizomes that developed into new plantlets. Clonal growth can significantly decrease the effective population size and hence contribute to the loss of genetic diversity and genetic differentiation via increased levels of genetic drift and inbreeding (Erickson and Hamrick, 2003).

\section{Implications for conservation}

The ultimate goal of conservation is to ensure the continuous survival of populations and to maintain their evolutionary potential. Information on current levels of genetic diversity of threatened and endangered species is essential for designing appropriate strategies for conservation (Hamrick and Godt, 1989; Francisco-Ortega et al., 2000). Based on the genetic 
diversity and genetic differentiation, the following efficient and practical conservation strategies for the endangered species $S$. rhodoleuca are suggested. First, considering the high genetic differentiation and the limited gene flow in this species, the conservation strategy should aim to preserve all of the extant populations so that most of the genetic variability can be conserved. Because this species is highly vulnerable to environmental changes, and habitat fragmentation and small population sizes make it susceptible to the loss of genetic diversity, in situ conservation efforts should place more emphasis upon the protection of its habitats. Second, ex situ conservation based on seed harvest should be carried out. Germplasm resources should be established with seeds from multiple sources with the purpose of capturing most of the genetic variability for future artificial cultivation. Third, reintroduction is recommended for most of the populations that express a decline tendency (Chai et al., unpublished data). Artificially propagated plants that are recruited from local seed sources are more likely to exhibit increased fitness than non-local genotypes in particular environments. Consequently, we suggest that care should be taken to separate seedlings from different populations and reintroduce seedlings only into their original parental localities. Considering the critical situation of $S$. rhodoleuca, probably the safest way to preserve the species is through a combination of all of these approaches.

\section{ACKNOWLEDGMENTS}

We thank Mr. Z.M. Wang for comments on the manuscript and language revision. Research supported by the National Natural Science Foundation of China (\#31260086) and the Science Foundation for the Youth of Guangxi (\#0832075).

\section{REFERENCES}

Chai SF, Jiang YS, Wei X, Wang ML, et al. (2010). Seed germination characteristics of endangered plant Sinia rhodoleuca. Chin. J. Ecol. 29: 233-237.

Dong YH, Chen JM, Gituru RW and Wang QF (2007). Gene flow in populations of the endangered aquatic fern Ceratopteris pteridoides in China as revealed by ISSR markers. Aquat. Bot. 87: 69-74.

Doyle J and Doyle JL (1988). Isolation of plant DNA from fresh tissue. Am. J. Bot. 75: 1238.

Ellstrand NC and Elam DR (1993). Population genetic consequences of small population size: implications for plant conservation. Ann. Rev. Ecol. Syst. 24: 217-242.

Erickson DL and Hamrick JL (2003). Genetic and clonal diversity for Myrica cerifera along a spatiotemporal island chronosequence. Heredity 90: 25-32.

Fen WC and Amaral MCE (1984). Ochnaceae. In: Flora of China. Vol. 12 (Mei GF, ed.). Science Press, Beijing, 302-308.

Feyissa T, Nybom H, Bartish IV and Welander M (2007). Analysis of genetic diversity in the endangered tropical tree species Hagenia abyssinica using ISSR markers. Genet. Resour. Crop Evol. 54: 947-958.

Fischer M, Husi R, Prati D, Peintinger M, et al. (2000). RAPD variation among and within small and large populations of the rare clonal plant Ranunculus reptans (Ranunculaceae). Am. J. Bot. 87: 1128-1137.

Francisco-Ortega J, Santos-Guerra A, Kim SC and Crawford DJ (2000). Plant genetic diversity in the Canary Islands: a conservation perspective. Am. J. Bot. 87: 909-919.

Frankham R, Ballou JD and Briscoe DA (2002). Introduction to Conservation Genetics. Cambridge University Press, Cambridge.

Fu LG (1992). Plants Red Book of China - Rare Endangered Plants. Science Press, Beijing.

Furches MS, Wallace LE and Helenurm K (2009). High genetic divergence characterizes populations of the endemic plant Lithophragma maximum (Saxifragaceae) on San Clement Island. Conserv. Genet. 10: 115-126.

Gupta M, Chyi Y-S, Romero-Severson J and Owen JL (1994). Amplification of DNA markers from evolutionarily diverse genomes using single primers of simple-sequence repeats. Theor. Appl. Genet. 89: 998-1006.

Hamrick JL and Godt MJW (1989). Allozyme Diversity in Plants. In: Plant Population Genetics (Brown AHD, Clegg MT, 
Kahler AL and Weir BS, eds.). Breeding and Genetic Resources, Sunderland, 123.

Hao B, Li W, Mu LC, Li Y, et al. (2006). A study of conservation genetics in Cupressus chengiana, an endangered endemic of China, using ISSR markers. Biochem. Genet. 44: 31-45.

Haque I, Bandopadhyay R and Mukhopadhyay K (2010). Population genetic structure of the endangered and endemic medicinal plant Commiphora wightii. Mol. Biol. Rep. 37: 847-854.

Harris J (1999). RAPDs in Systematics - a Useful Methodology? In: Molecular Systematics and Plant Evolution (Hollingsworth PM, Bateman RM and Gornall RJ, eds.). Taylor and Francis, London, 221-228.

He KJ and Li YD (2005). Plant resources of national protection grade I in Guangdong Province. J. Trop. Subtrop. Bot. 13: 519-525.

Huang Y, Zhang CQ and Li DZ (2009). Low genetic diversity and high genetic differentiation in the critically endangered Omphalogramma souliei (Primulaceae): implications for its conservation. J. Syst. Evol. 47: 103-109.

Jeong JH, Kim EH, Guo WH, Yoo KO, et al. (2010). Genetic diversity and structure of the endangered species Megaleranthis saniculifolia in Korea as revealed by allozyme and ISSR markers. Plant Syst. Evol. 289: 67-76.

Liang LL (2006). Rare Species Sauvagesia rhodoleuca. Guangxi Forestry 4: 49.

Loveless MD and Hamrick JL (1984). Ecological determinants of genetic structure in plant populations. Ann. Rev. Ecol. Syst. 15: 65-69.

Maki M and Horie S (1999). Random amplified polymorphic DNA (RAPD) markers reveal less genetic variation in the endangered plant Cerastium fischerianum var. molle than in the widespread conspecific C. fischerianum var. fischerianum (Caryophyllaceae). Mol. Ecol. 8: 145-150.

McDermott JM and McDonald BA (1993). Gene flow in plant pathosystems. Ann. Rev. Phytopathol. 31: 353.

McNeely JA, Miller KR, Reid WV, Mittermeier RA, et al (1990). Conserving the World's Biological Diversity. World Conservation Union, World Resources Institute, Conservation International, World Wildlife Fund US, and the World Bank, Washington.

Miller MP (1997). Tools for Population Genetic Analysis (TEPGA) Version 1.3. Department of Biological Sciences Northern Arizona University, Flagstaff.

Nei M (1972). Genetic distance between populations. Am. Nat. 106: 283-292.

Nei M (1973). Analysis of gene diversity in subdivided populations. Proc. Natl. Acad. Sci. U. S. A. 70: 3321-3323.

Nybom H and Bartish IV (2000). Effects of life history traits and sampling strategies on genetic diversity estimates obtained with RAPD markers in plants. Perspect. Plant Ecol. Evol. Syst. 3: 93-114.

Rohlf FJ (1998). NTSYSpc: Numerical Taxonomy and Multivariate Analysis System. Version 2.02. Exeter Software, Setauket.

Schaal BA, Hayworth DA, Olsen KM, Rauscher JT, et al. (1998). Phylogeographic studies in plants: problems and prospects. Mol. Ecol. 7: 465-474.

Shao JW, Chen WL, Peng YQ, Zhu GP, et al. (2009). Genetic diversity within and among populations of the endangered and endemic species Primula merrilliana in China. Biochem. Syst. Ecol. 37: 699-706.

Slatkin M (1987). Gene flow and the geographic structure of natural populations. Science 236: 787-792.

The State Forestry Administration and Ministry of Agriculture (1999). The list of Chinese urgently protected wild plants (the first group). Plant 5: 4-11.

Verma S and Rana TS (2011). Genetic diversity within and among the wild populations of Murraya koenigii (L.) Spreng., as revealed by ISSR analysis. Biochem. Syst. Ecol. 39: 139-144.

Wang CM, Huang SX and Wang Y (1994). The investigation and study on the germplasm resources of national precious, rare and endangered plants in Guangxi. Guihaia 14: 277-288.

Wei X, Wei JQ, Cao HL, Li F, et al. (2005). Genetic diversity and differentiation of Camellia euphlebia (Theaceae) in Guangxi, China. Ann. Bot. Fennici 42: 365-370.

Wolfe AD and Liston A (1998). Contributions of PCR-Based Methods to Plant Systematics and Evolutionary Biology. In: Molecular Systematics of Plants. II. DNA Sequencing (Soltis DE, Soltis PS and Doyle JJ, eds.). Kluwer Academic Publishers. Norwell, 43-86.

Xiao M, Li Q, Wang L, Guo L, et al. (2006). ISSR analysis of the genetic diversity of the endangered species Sinopodophyllum hexandrum (Royle) Ying from western Sichuan province, China. J. Integr. Plant Biol. 48: 11401146.

Yeh FC, Yang RC, Boyle TBJ and Ye ZH (1997). POPGENE, the User-Friendly Shareware for Population Genetic Analysis. Molecular Biology and Biotechnology Centre, University of Alberta, Calgary.

Yu HH, Yang ZL, Sun B and Liu RN (2011). Genetic diversity and relationship of endangered plant Magnolia officinalis (Magnoliaceae) assessed with ISSR polymorphisms. Biochem. Syst. Ecol. 39: 71-78.

Zeng DJ, Zhao RF, Chai SF, Chen ZY, et al. (2010). Study on cutting propagation of the endangered plant Sinia rhodoleuca. Seed 29: 80-82. 